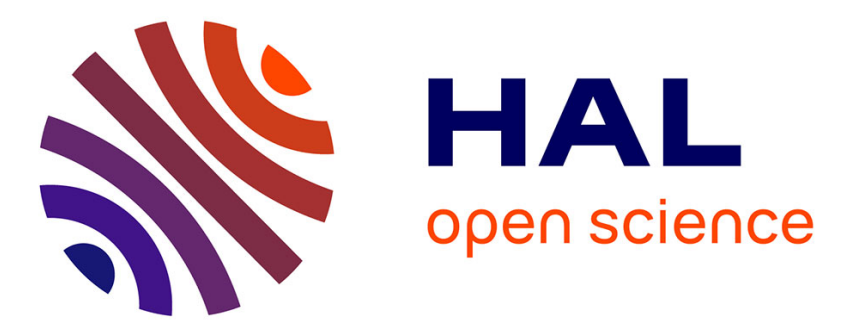

\title{
The importance of endothermic pyrolysis reactions in the understanding of diesel spray combustion
}

Kieran P Somers, Henry J Curran, Ultan Burke, Colin Banyon, Hichem Hakka, Frederique Battin-Leclerc, Pierre-Alexandre Glaude, Shaun Wakefield, Roger F Cracknell

\section{To cite this version:}

Kieran P Somers, Henry J Curran, Ultan Burke, Colin Banyon, Hichem Hakka, et al.. The importance of endothermic pyrolysis reactions in the understanding of diesel spray combustion. Fuel, 2018, 224, pp.302 - 310. 10.1016/j.fuel.2018.02.173 . hal-01920926

\section{HAL Id: hal-01920926 https://hal.science/hal-01920926}

Submitted on 13 Nov 2018

HAL is a multi-disciplinary open access archive for the deposit and dissemination of scientific research documents, whether they are published or not. The documents may come from teaching and research institutions in France or abroad, or from public or private research centers.
L'archive ouverte pluridisciplinaire HAL, est destinée au dépôt et à la diffusion de documents scientifiques de niveau recherche, publiés ou non, émanant des établissements d'enseignement et de recherche français ou étrangers, des laboratoires publics ou privés. 


\section{Diesel Spray Combustion}

3 Kieran P. Somers ${ }^{\mathrm{a}}$, Henry J. Curran ${ }^{\mathrm{a}}$, Ultan Burke ${ }^{\mathrm{a}}$, Colin Banyon ${ }^{\mathrm{a}}$, Hichem M. Hakka ${ }^{\mathrm{b}, \mathrm{c}}$, Frédérique

$4 \quad$ Battin-Leclerc $^{\mathrm{b}}$, Pierre-Alexandre Glaude ${ }^{\mathrm{b}}$, Shaun Wakefield ${ }^{\mathrm{c}}$, Roger F. Cracknell ${ }^{\mathrm{c}}$

5 a Combustion Chemistry Centre, School of Chemistry \& Ryan Institute, National University of Ireland

6 Galway, Ireland, H91 TK33.

7 'baboratoire Réactions et Génie des Procédés, UMR 7274 CNRS - Université de Lorraine, 1 rue Grandville, 854000 Nancy, France

$9 \quad$ 'Shell Global Solutions, UK

11 Corresponding Author: Kieran P. Somers, Combustion Chemistry Centre, School of Chemistry \& Ryan 12 Institute, National University of Ireland Galway, Ireland. (Kieran.Somers@ nuigalway.ie, Tel: +353 49 4026)

\section{Abstract}

The significance of pyrolysis reactions in the early stages of diesel combustion has received

little attention in the literature, which warrants a mechanistic investigation of the controlling chemistry along with its potential impacts on the overall combustion process in engines. Experiments were performed in a constant volume vessel to probe these pyrolytic reactions, where diesel fuel sprays were injected into air at varied pressures and temperatures chosen to represent an engine operating at various loads. The pressure inside the vessel was found to decrease immediately following the start of injection before increasing as the exothermic heat release occurs. The initial pressure decrease has been conventionally attributed to an evaporative cooling effect of the diesel spray, but the objective of this paper is to test the hypothesis that endothermic pyrolysis reactions can make a significant contribution to the observed pressure decrease.

The addition of $1 \%$ of the cetane booster, 2-ethylhexylnitrate (2-EHN), to the fuel was found 
1 increase the magnitude of the initial pressure decrease compared to conventional diesel fuel. Detailed

2 chemical kinetic modeling shows that the effects observed in the constant volume vessel can 3 plausibly be attributed to pyrolysis reactions, and that the addition of 2-EHN to the base fuel 4 enhances their influence. The modelling results also imply that the influence of these pyrolysis 5 reactions increases with increasing temperature, pressure, the alkyl chain length of the base fuel, and 6 the amount of any radical initiator in the fuel.

\section{$9 \quad$ Keywords}

10 Diesel, Spray, Ignition Delay Time, Pyrolysis Reactions, Cetane Booster 


\section{1. Introduction}

Solid, liquid, and gaseous fuels are known to pyrolyse, altering their molecular structure without significant oxidation, even though oxygen-containing species may be present. Such pyrolysis

4 reactions are generally endothermic as a result of the energy required to break chemical bonds,

5 resulting in their rate constants and hence rates being highly temperature dependent. The pyrolysis

6 and rich oxidative combustion of fuels have been widely investigated in shock tubes [1,2], jet-stirred

7 reactors [3-5] and flow reactors [6, 7]. MacDonald et al. [1] report that test gas mixture temperatures

8 in a shock tube can be lower than the initial temperatures immediately behind the reflected shock

9 because of endothermic reaction. However the implications of endothermicity for practical combustion systems have been largely confined to the study of aviation fuels, where it has been suggested that endothermicity can help scramjet cooling [8] and thermal protection in general [9]. Constant-volume combustion vessels have been employed to study the physical and chemical properties associated with liquid fuel combustion under conditions relevant to spark and compression

14 ignition engines. When a liquid fuel is injected into such a vessel under conditions relevant to diesel fuels and engines, there is typically an initial decrease in the measured gas pressure owing to fuel vaporisation, followed by an increase in pressure due to the occurrence of exothermic chemical

17 reactions which lead to autoignition, Figure 1 . The overall ignition delay time is usually defined as the period between the start of injection, to the point at which the pressure has recovered to its original value, and this is the protocol adopted in the measurement of derived cetane number using the Ignition Quality Tester device [10]. 


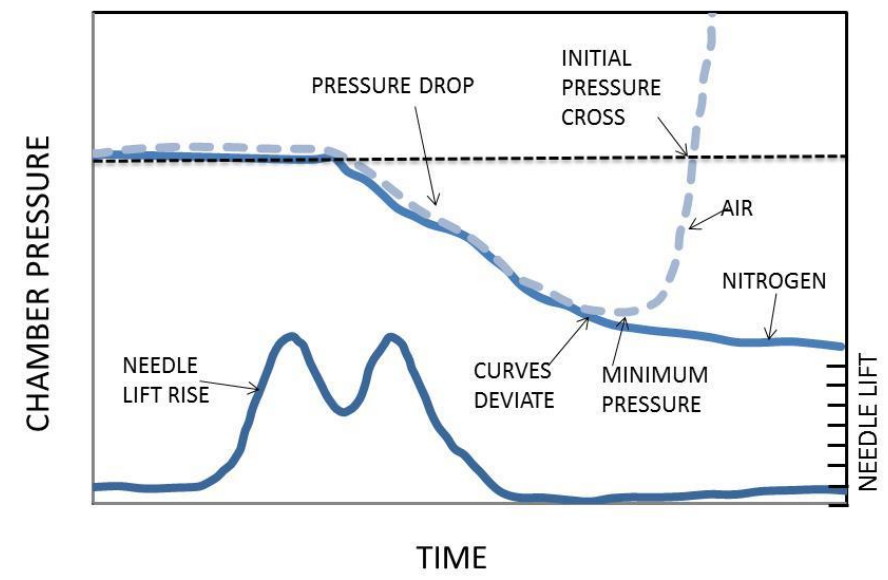

2 Figure 1: Pressure-Time records and injection-nozzle needle-lift trace with identification of the various points of pnterest. Adapted with permission from [14].

Various attempts have been made to separate the physical and chemical processes which control the overall ignition behaviour into a physical delay which represents the fuel evaporation and fuel-oxidiser mixing processes, and a chemical delay which accounts for the gas-phase chemical reactions which ultimately lead to combustion. Experiments are often repeated in an atmosphere of nitrogen, so that the exothermic oxidation reactions cannot take place and the divergence of the nitrogen pressure trace from the combusting pressure trace is used as the demarcation between the end of the physical delay and the start of the chemical delay $[11,12]$.

Other studies [13-16] have defined the post-injection time step at which pressure reaches a minimum as being the point where the measured pressure signal transitions from being purely evaporation/mixing controlled to being purely chemically controlled. Although, the example in Figure 1 shows the minimum in the pressure trace occurring at approximately the same point as the divergence of the nitrogen and air curves, more recent work for $n$-heptane has shown that the pressure minimum can occur considerably later than the point at which the nitrogen and air curves diverge [17].

Usually the initial pressure decrease is attributed only to the evaporation of the fuel $[15,16]$ but Zheng et al. [17] acknowledge the additional possibility of endothermic reactions, in experiments 
1 in both air and nitrogen. It is already clear from the previous discussion that any attempted

2 demarcation between physical and chemical ignition delay times is somewhat arbitrary but the

3 existence of chemical reactions during the so-called physical delay may undermine the interpretation

4 of such experimental data unless differences arising from variation in chemical structure are 5 accounted for.

The objective of this work is to understand the influence of the addition of 2-EHN and its associated reactions on the combustion of diesel fuels and their components. Results are presented for 9 different conditions in a constant-volume vessel with varying bulk-gas pressure and temperature in which a standard diesel fuel is compared against a diesel fuel containing $1 \%$ of the cetane booster 2-ethylhexylnitrate (2-EHN). In all instances the addition of 2-EHN to the base-fuel leads to shorter total ignition delay times being measured, but in some cases a greater initial pressure decrease is observed during the so-called physical-delay stage. A greater pressure decrease due to enhanced fuel vaporisation is argued to be implausible due to the 2-EHN concentrations in the basefuel, and so the phenomenon can only be interpreted in terms of endothermic pyrolysis reactions, which are explored using detailed chemical kinetic models from the literature. needle lift sensor inside the injector monitors the injection event. The chamber pressure, chamber temperature, fuel pressure, chamber gas composition and injector pulse width can all be varied by the

\section{Experimental setup and results in a constant volume combustion chamber}

The Combustion Research Unit (CRU) in Shell Global Solutions is a constant-volume vessel, manufactured by Fueltech that can mimic combustion conditions in modern diesel engines CRU [18, 19]. A schematic diagram of the CRU is shown in Figure 2. The unit is supplied with a common rail injection system of type Bosch CRIP2 (Part No: 0445110157) and a 7 hole nozzle. Fuel is injected into the pressurized heated chamber where it mixes with hot air and ignites.

The combustion process is monitored with a pressure sensor inside the chamber whilst a operator. Before the fuel is injected, the chamber is filled with high-pressure air (or another gas) 
1 from an external air cylinder and heated to a pre-set temperature via two electric heaters. Some

2 technical parameters of the CRU are listed in Table 1.

Table 1: Operating parameters of the CRU

\begin{tabular}{lr}
\hline Parameter & CRU Mark II \\
\hline Initial chamber pressure & $2-75$ bar \\
Initial chamber wall temperature & $350-590^{\circ} \mathrm{C}$ \\
Fuel pressure & $200-1600 \mathrm{bar}$ \\
Main injection pulse width & $0.3-1.5 \mathrm{~ms}$ \\
Pilot injection pulse width & $0-1.4 \mathrm{~ms}$ \\
Pilot-main separation & $0.1-3.0 \mathrm{~ms}$ \\
\% Auxiliary gas & $0-100 \%$
\end{tabular}

4

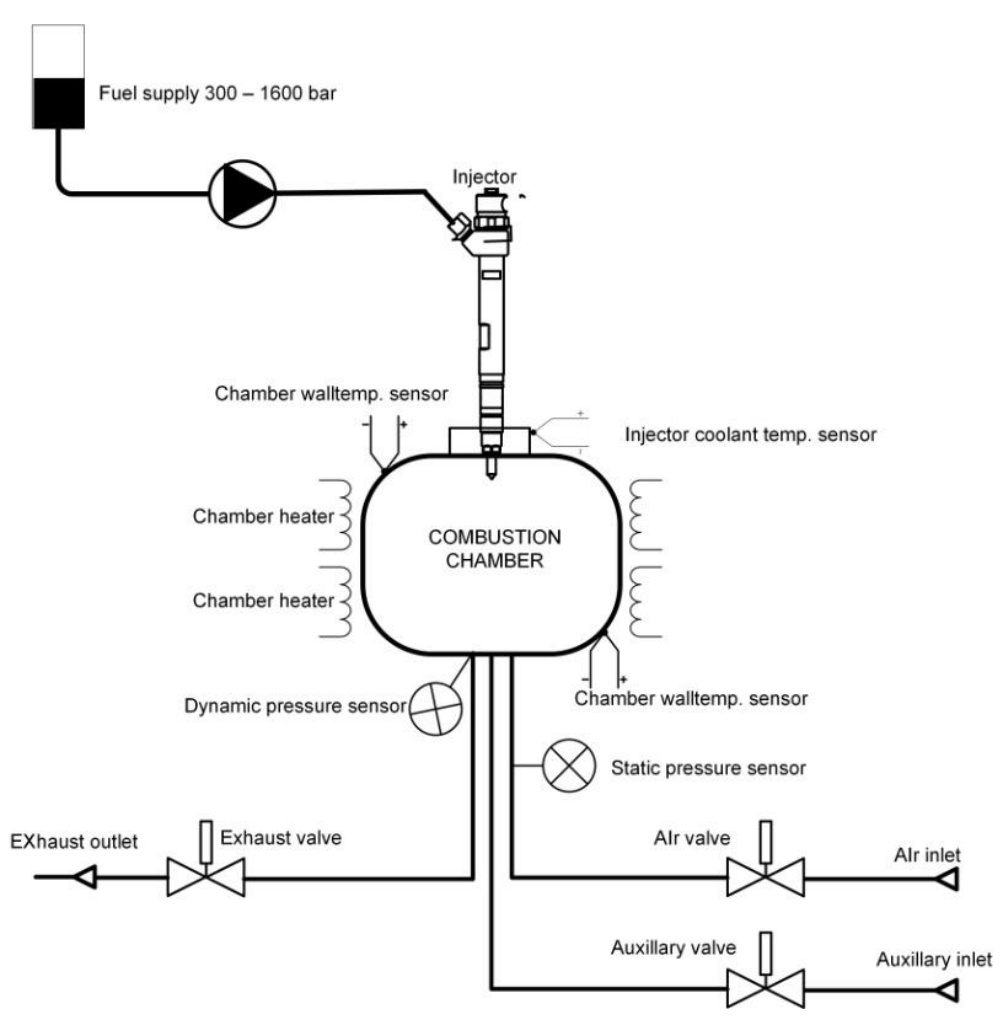

6 Figure 2: Schematic diagram of the Combustion Research Unit. Reproduced with permission from 7 Fueltech. 
The needle lift sensor and the two dynamic pressure sensors in the combustion chamber and

2 fuel line all sample at a rate of $50 \mathrm{kHz}$ (intervals of $0.02 \mathrm{~ms}$ ), giving outputs including needle lift,

3 chamber pressure and fuel pressure. The needle lift enables the measurement of the start of injection

4 (SOI) and the end of injection (EOI). The fuels used were a standard EN590 diesel and the EN590

5 diesel with $1 \%$ by mass of 2-EHN added. The CRU was operated at the conditions listed in Table 2,

6 and the diesel fuel properties are provided in ESI.

The global equivalence ratio $(\varphi)$ is very lean, around $\varphi=0.075$ for the 30 bar cases and leaner

8 still for the higher pressure cases.

Table 2: Experimental Conditions studied in CRU. Main injection only.

\begin{tabular}{ccccc}
\hline Condition & $T_{\text {wall }} /{ }^{\circ} \mathrm{C}$ & $p_{\text {chamb }}($ bar $)$ & $p_{\text {fuel }}(\mathrm{bar})$ & Inj Period $(\mu \mathrm{s})$ \\
\hline 1 & 590 & 30 & 900 & 900 \\
2 & 590 & 50 & 900 & 900 \\
3 & 590 & 75 & 900 & 900 \\
4 & 560 & 30 & 900 & 900 \\
5 & 560 & 50 & 900 & 900 \\
6 & 560 & 75 & 900 & 900 \\
7 & 530 & 30 & 900 & 900 \\
8 & 530 & 50 & 900 & 900 \\
9 & 530 & 75 & 900 & 900
\end{tabular}

10 

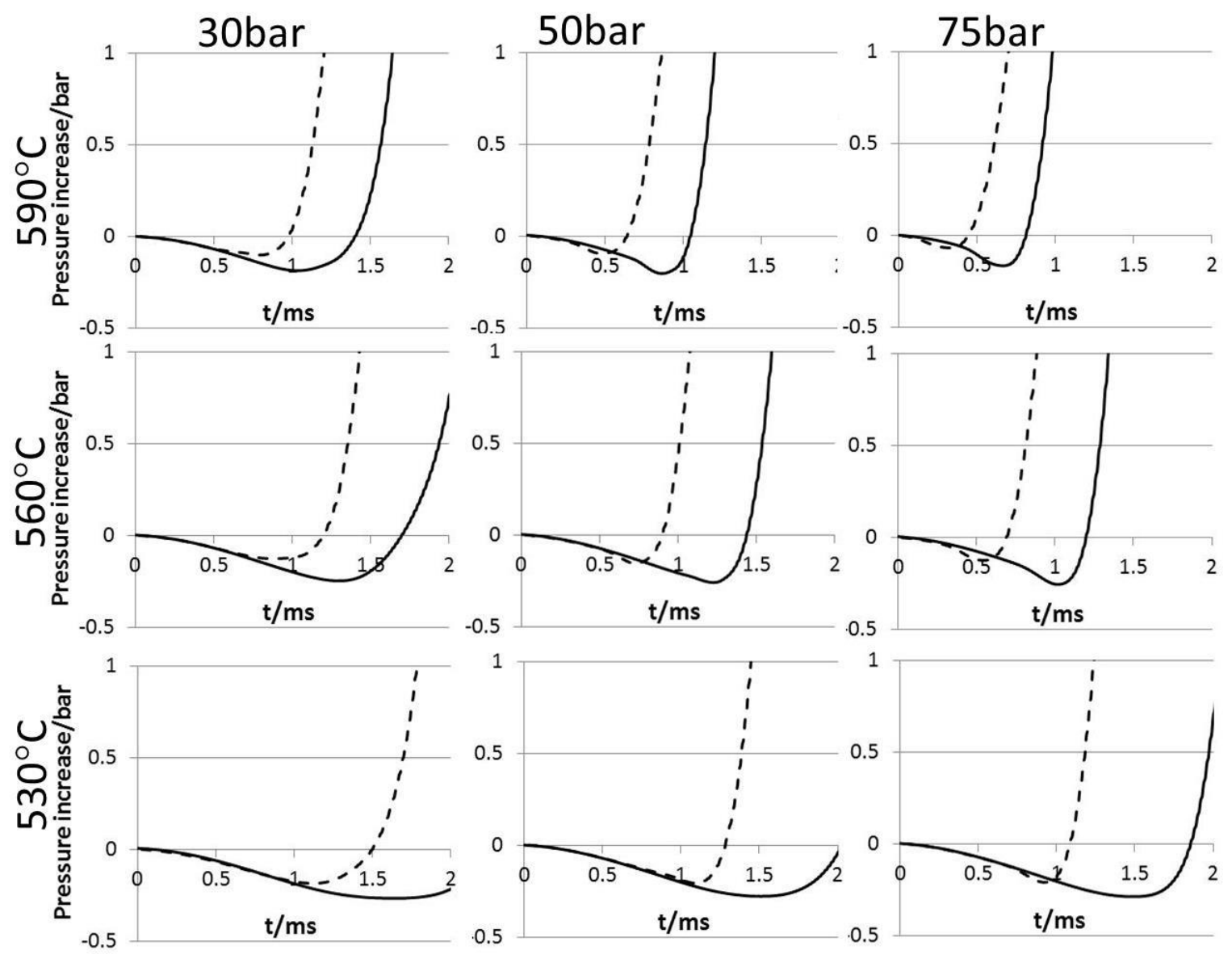

2 Figure 3: Pressure traces for the nine injection conditions in Table 2. The solid line is for EN590 diesel and the dashed line is for EN590 diesel with $1 \%$ mass 2-EHN.

Figure 3 shows that addition of 1\% 2-EHN shortens the ignition delay of the diesel for all of the conditions investigated. Increasing both the pressure and temperature also leads to a decrease in ignition delay for diesel fuels with and without 2-EHN - this is again fully expected and in line with previous findings on diesel primary reference fuels in the CRU $[18,19]$.

Asides from the expected trends in ignition delay time, Figure 3 also shows a divergence of

9 the measured pressure during the pressure decrease phase, and in particular one can observe that the

10 pressure decrease occurs faster for the fuels containing 2-EHN as the temperature and pressure

11 increases. Different rates of vaporisation cannot be ruled out as an explanation for the trends

12 observed in this work, but the latent heat of vaporisation of 2-EHN [20] is very similar to that of a

13 hydrocarbon of similar carbon number, and it is present in the fuel in relatively small quantities. 
1 Higgins et al. [21] used a constant volume vessel with optical access to study ignition, evaporation and mixing effects upon the addition of 2-EHN to diesel fuels. They found that the addition of 4000 ppm of 2-EHN to a ternary $n$-hexadecane/decaline/1-methylnaphtalene diesel surrogate had a limited influence on physical processes such as atomisation, fuel vaporisation, and turbulent mixing, but it

did lead to shorter ignition delay times, as found herein. Endothermic pyrolysis reactions therefore seem a plausible explanation for the experimental observations given that past studies imply no pronounced physical effect of 2-EHN addition to diesel fuels. It cannot be stated a priori that endothermic reactions involving both 2-EHN and the base diesel, or 2-EHN alone, are the cause of the observed effect but this will be explored subsequently.

\section{Chemical Kinetic Modeling}

Given the complex turbulence/chemistry interactions (spray formation and break-up, evaporation, mixing, ignition and flame chemistry) which are occurring simultaneously in our experiment, any attempt to model the results on a truly comparative basis would require a correspondingly complex computational approach. Here, the focus is on gas-phase chemical kinetic aspects of the experiment, and whilst the conditions of temperature, pressure, and fuel composition are imprecisely known in our experiment due to spatial inhomogeneity within the reactor, idealised chemical kinetic modeling can still be used to elucidate aspects of the fuel's combustion chemistry which may influence our experimental results. In order to study these effects and to interpret and inform the experimental observations at a more fundamental level, 0-D homogeneous batch reactor simulations have been carried out, under representative conditions of temperature $(T)$, pressure $(p)$, fuel mole fraction $\left(\chi_{F}\right)$, and fuel composition $\left(n-\mathrm{C}_{7} \mathrm{H}_{16} / n-\mathrm{C}_{16} \mathrm{H}_{34} / 2-\mathrm{EHN} / \mathrm{O}_{2} / \mathrm{N}_{2}\right)$.

In order to account for different hydrocarbon species which may preferentially evaporate during the course of our experiment, both $n$-heptane $\left(n-\mathrm{C}_{7} \mathrm{H}_{16}\right)$ and $n$-hexadecane $\left(n-\mathrm{C}_{16} \mathrm{H}_{34}\right)$ have been used as separate chemical surrogates for diesel, as is commonplace. Both the $n-\mathrm{C}_{7} \mathrm{H}_{16}$ and $n$ -

$\mathrm{C}_{16} \mathrm{H}_{34}$ kinetic models are sourced from the POLIMI library [22, 23]. A 2-EHN kinetic model has 
1 been added to these models to account for the influence of 2-EHN on the chemical kinetics and

2 thermodynamics which control the fuel oxidation, with kinetic and thermodynamic parameters

3 adopted from the work of Andrae [24]. Sub-mechanisms for $\mathrm{NO}_{x}$ and low molecular weight alkyl

4 nitrate species are pre-existing in the POLIMI databases.

Whilst the global fuel-air equivalence ratio is extremely lean, the chemical reactions which occur in the early stages of the experiment, and which coincide with the apparent endothermic effect observed experimentally, are likely to occur (a) at the interfaces between the liquid fuel-spray and

8 the super-critical oxidiser mixture, (b) before complete mixing has occurred, and (c) before the main

9 heat-release/ignition event is observed. At this fuel-air boundary, the mole fraction of fuel in the gas-

10 phase is likely to be infinitely rich, becoming increasingly fuel-lean as fuel components selectively 11 evaporate and diffuse into the bulk gas. Therefore, for a comprehensive understanding of the 12 chemical aspects of the experiment, simulations have been carried out for fuel mole fractions ranging 13 from near-infinitely-lean (as is the global equivalence ratio experimentally) to near-infinitely-rich (as 14 would be found at a liquid-air interface) limits. Evaporation is also quite dependent on the vapour 15 pressure of individual fuel components, and simulations will ultimately be presented for pressures 16 ranging from $1-75$ bar. 


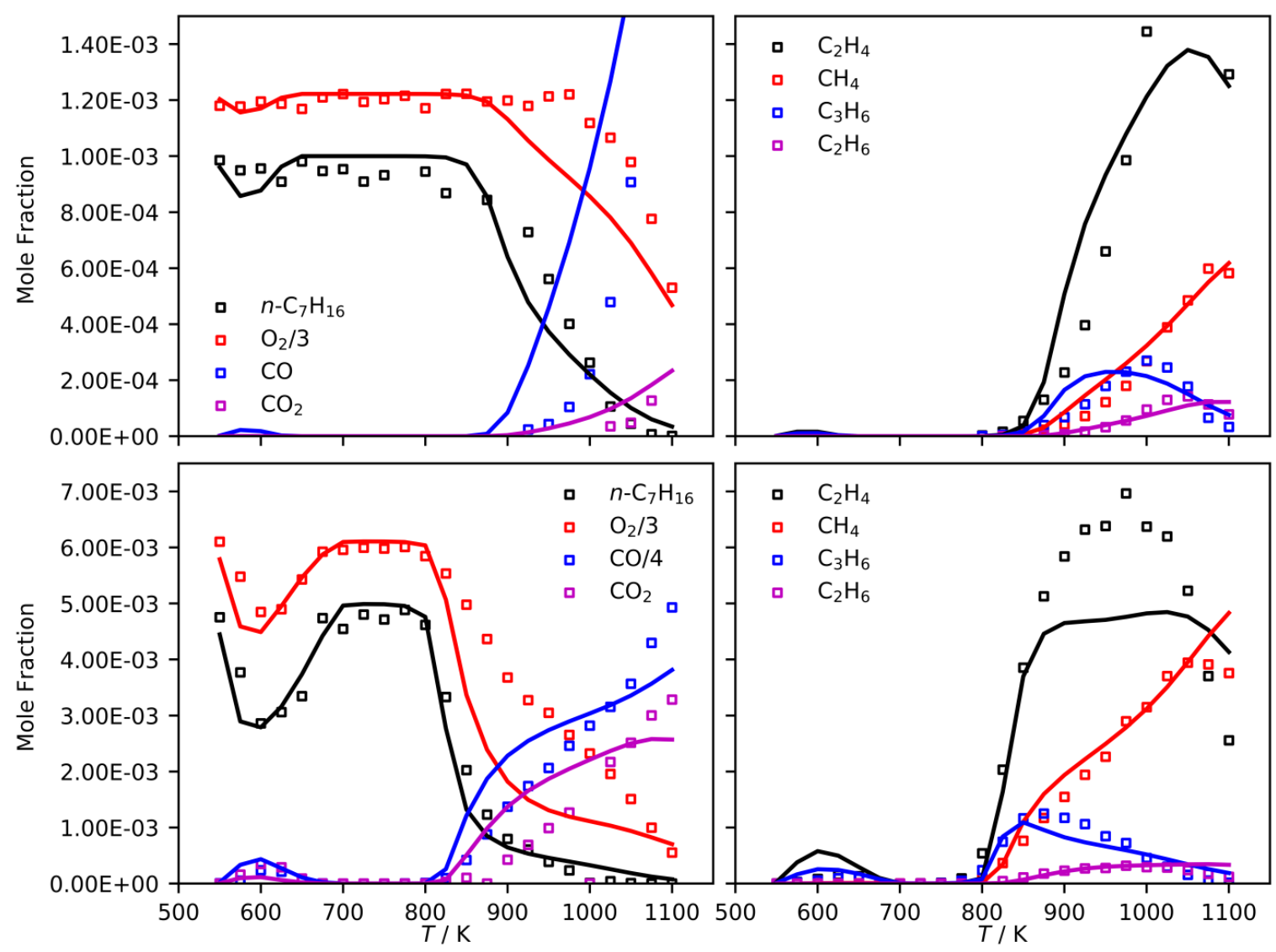

2 Figure 4: Comparison of the predictions of the reduced $n-\mathrm{C}_{7} \mathrm{H}_{16}$ kinetic model of Ranzi et al. [22] with

3 jet-stirred reactor measurements of ultra-rich $n-\mathrm{C}_{7} \mathrm{H}_{16} / \mathrm{O}_{2} / \mathrm{He}$ oxidation of Hakka et al. [5] at 1.06 bar, $\varphi$

$4=3$ in helium bath gas. Top: Residence time $=1 \mathrm{~s}$, mole fraction of fuel $1 \times 10^{-3}$. Bottom: Residence time

$5=2 \mathrm{~s}$, mole fraction of fuel $5 \times 10^{-3}$.

Figure 4 compares the performance of the $n-\mathrm{C}_{7} \mathrm{H}_{16}$ kinetic model used to the ultra-rich measurements of $n-\mathrm{C}_{7} \mathrm{H}_{16}$ oxidation in a jet-stirred reactor (JSR) [5]. Whilst the kinetic model tends

8 to over-predict the rate of oxidation at temperatures above $850 \mathrm{~K}$, it can capture the qualitative trends observed in the distribution of pyrolysis and oxidation products. Figure S1-S3 of the ESI shows a comparison of the performance of several detailed kinetic models with experimental JSR data

11 measured under fuel-rich conditions [5], illustrating that the reduced $n$ - $\mathrm{C}_{7} \mathrm{H}_{16}$ kinetic model of Ranzi et al. [22] shows a quite favourable performance versus the more detailed kinetic models of Hakka et al. [5] and Zhang et al. [25], but at a fraction of the computational cost. Based on the validation 14 presented above, it is likely that the kinetic model of Ranzi et al. [22] will under-predict the extent 
1 of endothermic pyrolysis reactions, but ultimately, a computationally tractable, consistently

2 developed kinetic scheme which can predict the trends in pyrolysis/oxidation product distributions

3 for fuels of substantially different molecular weight is required. The predictions of the above data

4 give confidence in the POLIMI library for understanding the gas-phase chemical aspects of the 5 experiment.

With the exception of the JSR data above, all simulations were carried out assuming a constant-pressure/constant-temperature reactor where heat release due to chemical reaction is not allowed to affect the thermodynamic state of the mixture. This approach was taken so that a steady state condition could be reached with respect to the extent of chemical reaction for a given initial $T / p$, and so that any exothermicity, endothermicity, and characteristic timescales could be understood 11 from an idealised chemical kinetics perspective. For each simulation, volumetric heat-release rates (J $12 \mathrm{~m}^{-3} \mathrm{~s}^{-1}$ ) due to gas-phase chemical reaction were computed at every time-step, and integrated with respect to the specific volume $\left(\mathrm{m}^{3} \mathrm{~kg}^{-1}\right)$ of the reactor and time (s), allowing for the energy change per mass of mixture $\left(\mathrm{J} \mathrm{kg}^{-1}\right)$ to be computed as a function of time. In all cases, a negative integrated heat-release rate, or enthalpy of reaction henceforth, indicates a region of exothermicity and viceversa for regions where a positive reaction enthalpy are observed. at 3.76:1 and fuel mole fractions, $\chi_{F}$, were varied from 0.01 to 0.99 . The equivalence ratio as a function of fuel fraction is therefore given by $\varphi\left(\chi_{F}\right)=n\left(4.76 \chi_{F}\right) /\left(1-\chi_{F}\right)$ where $n$ is the number of moles of $\mathrm{O}_{2}$ required to stoichiometrically combust 1 mole of fuel. Values of $n$ and $\varphi(\chi)$ are tabulated

21 for each mixture in ESI, and the Figures presented in the main text are also presented as a function of equivalence ratio therein. The total simulation time was fixed at $10 \mathrm{~ms}$, although as will be shown, the majority of exothermic and endothermic chemical reaction tended to occur on millisecond/submillisecond timescales, with 2-EHN existing on sub-microsecond timescales. All simulations were carried out with the Cantera package [26]. 
Figure 5 shows the evolution of the heat-release rate with time for a typical gas-phase combustion experiment, stoichiometric $(\varphi=1)$ fuel-air mixtures, for both $n-\mathrm{C}_{7} \mathrm{H}_{16}$ and $n$ - $\mathrm{C}_{16} \mathrm{H}_{34}$

3 fuels. The results show that the longer chain alkane, $n-\mathrm{C}_{16} \mathrm{H}_{34}$, reacts on a shorter timescale and with

4 a more pronounced maximum heat release rate than its shorter-chain counterpart, $n-\mathrm{C}_{7} \mathrm{H}_{16}$. With the 5 addition of 2-EHN to these pure alkanes, one can initially observe a three-fold effect-(a) there is an 6 initial region of endothermicity, which is not observed for the pure fuels, (b) there is a subsequent 7 acceleration of the heat-release stage, due to generation of a radical pool which initiates lowtemperature chain-branching, and (c) there is a slight perturbation to the magnitude of the peak heat-

9 release rate from addition of this cetane booster to the mixture. Addition of even small quantities of 2-EHN to short- and long-chain alkane fuel components clearly results in perturbations to the time11 dependent behaviour of the system. Whilst this analysis shows some interesting behaviours, which 12 are in-line with the experimental observations, a more detailed modeling analysis shows more complex dependencies.

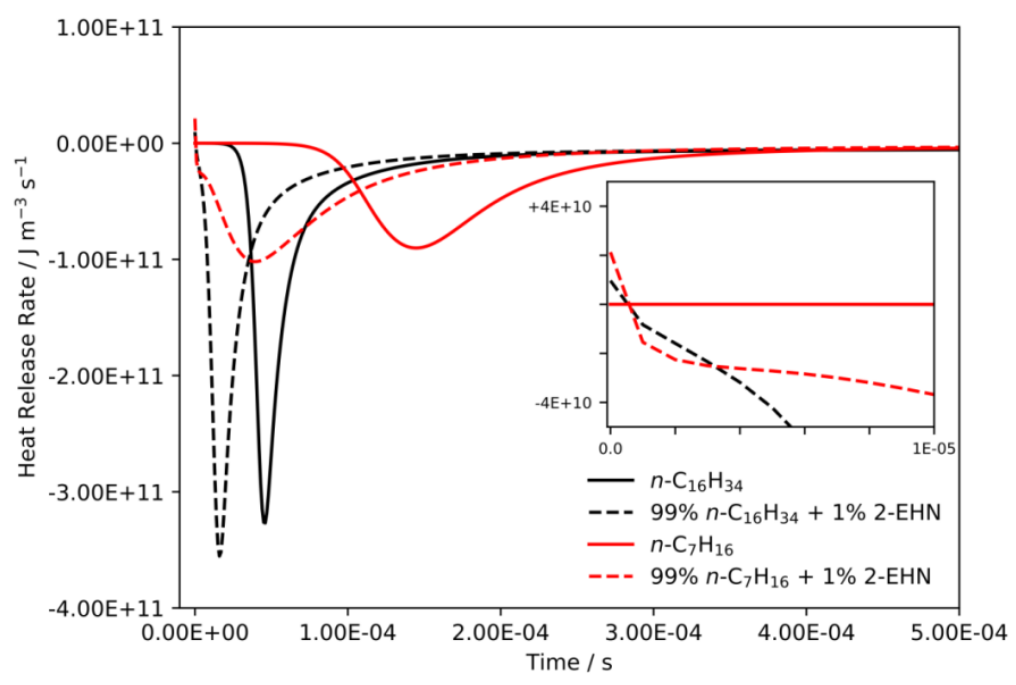

Figure 5: Gas-chemistry heat release rates $\left(\mathrm{J} \mathrm{m}^{-3} \mathrm{~s}^{-1}\right)$ for stoichiometric fuel-air mixtures of $\boldsymbol{n}$-heptane and $n$-hexadecane, with and without $1 \%$ 2-ethylhexylnitrate additive, at $T / K=863$ and $p / b a r=75$. Inset: heat release rates vs. time for the first $10 \mu$ s of chemical reaction, units for $x$ and $y$ axes are the same as main figure. 


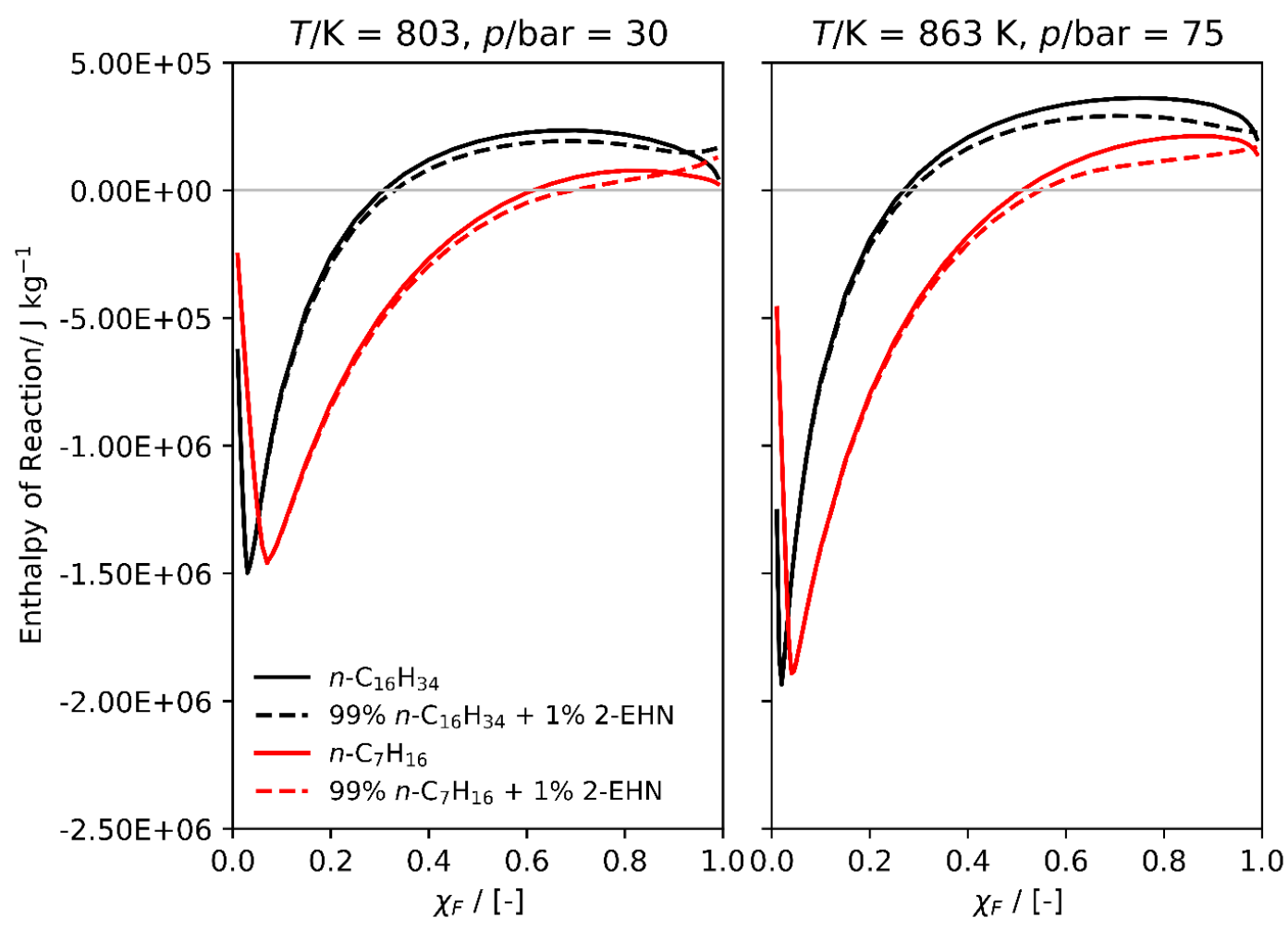

2 Figure 6: Reaction enthalpies as a function of fuel mole fraction at the lowest (left) and highest (right)

3 experimental conditions of temperature and pressure. A positive reaction enthalpy indicates net4 endothermic reaction, and vice-versa for a negative reaction enthalpy.

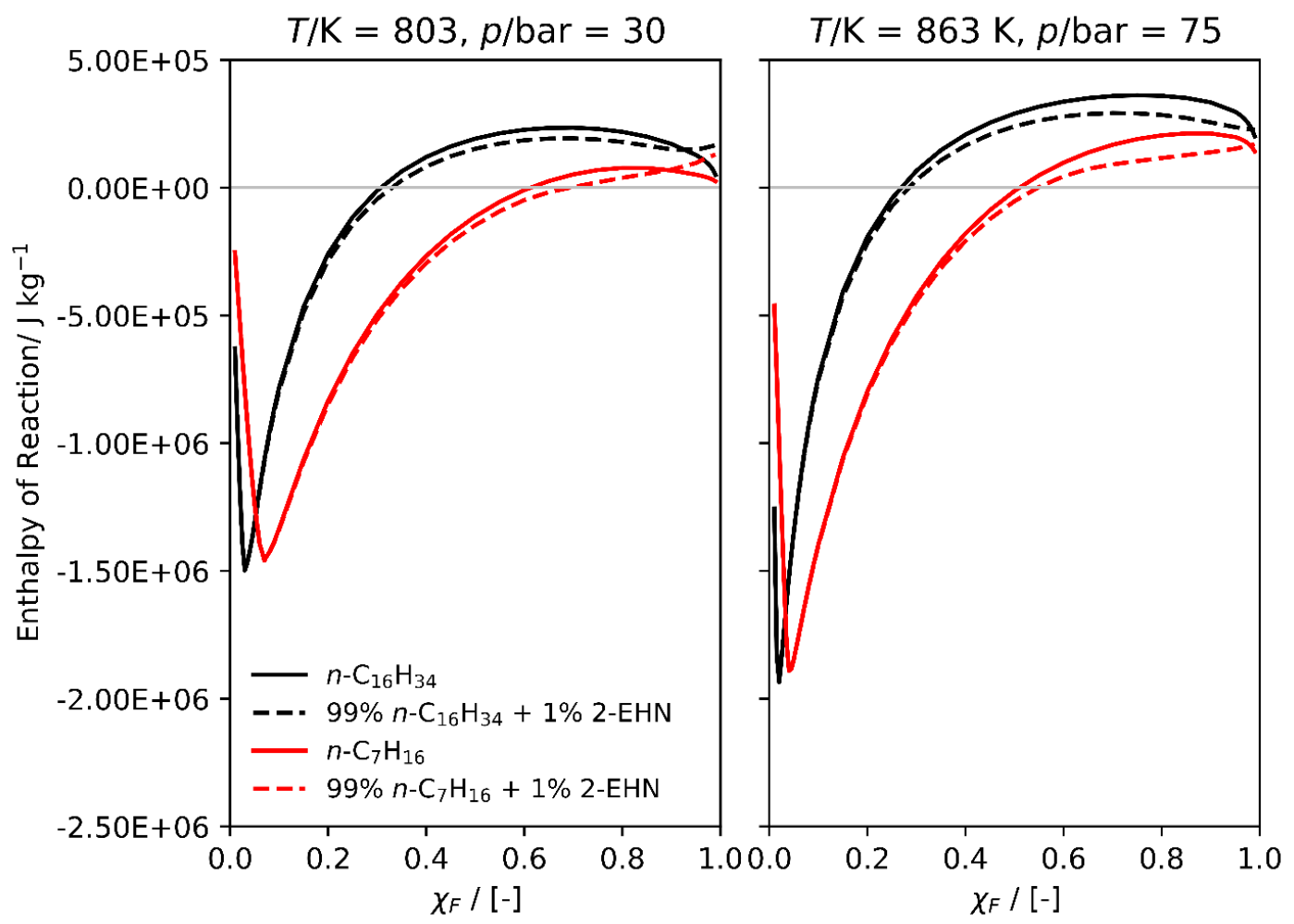


Figure 6 shows net enthalpy changes after $10 \mathrm{~ms}$ of chemical reaction, for $n-\mathrm{C}_{7} \mathrm{H}_{16}$ and $n$ -

$2 \mathrm{C}_{16} \mathrm{H}_{34}$ fuel-air mixtures with and without $1 \%$ mole fraction of 2-EHN present, and at the extremes of bulk-gas temperatures and pressures studied in the CRU. All energy changes are normalised by total mass of the mixture, and differences in computed enthalpy changes for the four fuels tested under these two conditions are due to differences in the underlying chemical kinetics and thermodynamics of the individual systems, and not due to differences in the initial gas density or temperature. For all cases, there is a pronounced peak in exothermicity for fuel mole fractions less than 0.1 , with fuelconversion becoming net-endothermic above a critical ratio of fuel: $\mathrm{O}_{2}$. Therefore, as one increases the fuel fraction there are regions where the oxidation of the hydrocarbon transitions from being complete to partial, and from net-exothermic to net-endothermic. Viewed from the perspective of our CRU experiments, for highly rich mixtures chemical reaction will tend to be net-endothermic when concentrations of $\mathrm{O}_{2}$ are low with respect to the fuel concentration, with reaction transitioning to becoming net-exothermic and igniting, as one increases the ratio of $\mathrm{O}_{2}$ :fuel, which would occur with increased levels of mixing.

There are several other trends of relevance to our experiments. In terms of the magnitude of the maximum heat release, there is little difference between $n-\mathrm{C}_{7} \mathrm{H}_{16}$ and $n-\mathrm{C}_{16} \mathrm{H}_{34}$ other than the mole fraction for which peak heat release is obtained. However, with increasing gas-phase fuel mole fraction, it is clear that one can expect longer-chain components to undergo the transition from netexothermic to net-endothermic combustion at a lower fuel mole-fraction than shorter-chain components. Irrespective of fuel structure, the magnitude of both exothermicity and endothermicity is increased as one increases the pressure from 30 bar to 75 bar, and the temperature from $803 \mathrm{~K}$ to $863 \mathrm{~K}$. This trend is clearly visible in the experiment, where the magnitude of the pressure decrease measured experimentally increases with increasing pressure and temperature. For both pressures/temperatures presented in Figure 6, the addition of 2-EHN to the base fuel has a limited effect on the global energy change when reaction is net-exothermic, although Figure 5 clearly shows 
that the addition of 2-EHN accelerates the onset of this behavior in line with the acceleration in

2 ignition delay time measured experimentally.

However, the influence of 2-EHN is more pronounced at high fuel mole fractions, where its

addition can reduce the extent of endothermicity under some conditions, but at the extremes of fuelrichness, as are likely in the early stages of our CRU experiments, the addition of 2-EHN increases and accelerates endothermicity relative to the base fuel.
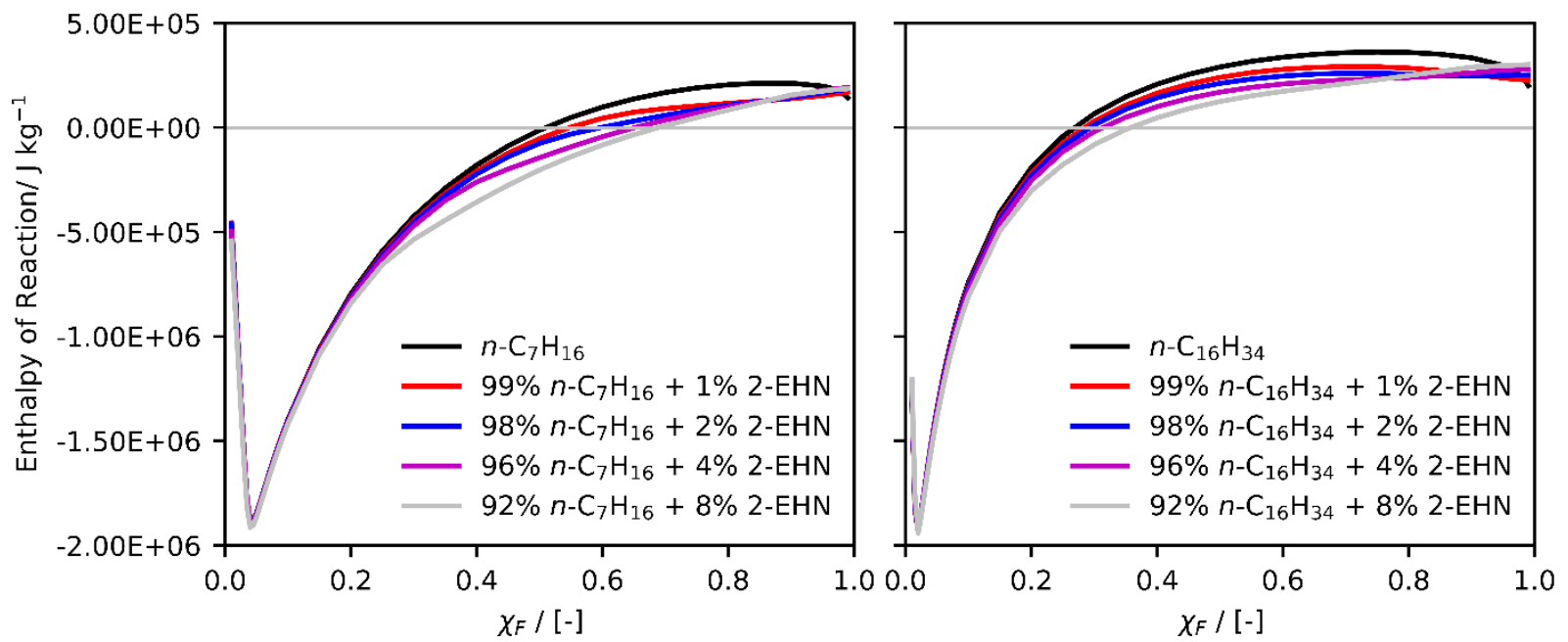

Figure 7: Influence of increasing gas-phase 2-EHN mole fraction on the reaction enthalpy for a $10 \mathrm{~ms}$ simulation of $n-\mathrm{C}_{7} \mathrm{H}_{16}$ and $n-\mathrm{C}_{16} \mathrm{H}_{34}$ fuel-oxidiser mixtures at $T / \mathrm{K}=863$ and $p / b a r=75$.

Figure 7 in turn delineates the influence of increasing gas-phase 2-EHN mole fraction for $n$ $\mathrm{C}_{7} \mathrm{H}_{16}$ and $n-\mathrm{C}_{16} \mathrm{H}_{34}$ fuel-oxidiser mixtures at $863 \mathrm{~K}$ and 75 bar, for a simulation time of $10 \mathrm{~ms}$. Increasing the 2-EHN content of each mixture tends to have a net-exothermic effect on the thermodynamics of the system, with the exception of highly fuel-rich conditions where there is insufficient oxygen present in the mixture for significant oxidative low-temperature chain-branching reactions to occur. Whilst the net effect of 2 -EHN addition for a given fuel/T/p/ $\chi_{F}$ condition is effectively linear with increasing 2-EHN content, this is not the case in terms of the underlying timedependent behaviour, as illustrated in Figure 8 and Figure 9. Figure 8 provides a detailed timedependent analysis of the perturbative influence of 2-EHN on the combustion of $n-\mathrm{C}_{16} \mathrm{H}_{34} / \mathrm{O}_{2} / \mathrm{N}_{2}$ 
mixtures. Four representative cases are presented for varying total fuel mole fraction, $\chi_{F}=0.02$,

2 which corresponds to the condition of maximum exothermicity, $\chi_{F}=0.99$ where the mixture is near-

3 infinitely rich and initial pyrolytic reaction of the base-fuel and 2-EHN will be most pronounced, and

4 two intermediate conditions, $\chi_{F}=0.4$ and $\chi_{F}=0.8$, where the effects of increasing 2-EHN fraction on

5 the thermodynamics of the system shows complex dependencies on time.
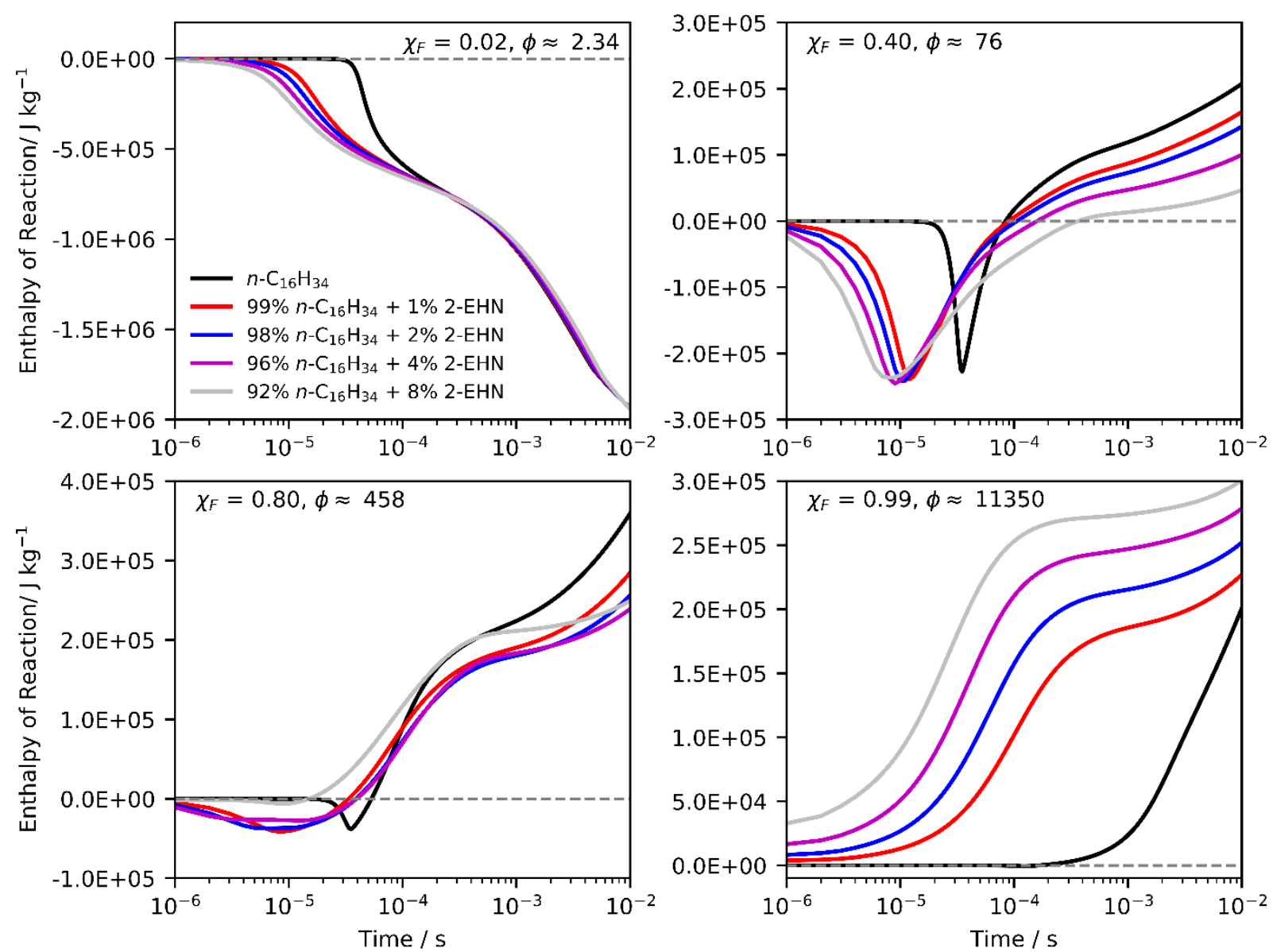

Figure 8: Time-dependent reaction enthalpy for mixtures with varying $n-\mathrm{C}_{16} \mathrm{H}_{34}$ :2-EHN ratios and

fuel:oxidiser ratios at $T / \mathrm{K}=863$ and $p / \mathrm{bar}=75$.

The exothermic $\chi_{F}=0.02$ case clearly illustrates the cetane-boosting qualities of 2-EHN

11 relative to the base-fuel via a marked acceleration in the onset of chemical heat-release. Contrary to

12 that, the $\chi_{F}=0.99$ results are compelling, illustrating that in the absence of $\mathrm{O}_{2}$, endothermic pyrolysis

13 of a base fuel will occur, but the extent and rate at which this happens is significantly increased with 
1 increasing 2-EHN content, a trend which is central to our experimental observations. The $\chi_{F}=0.4$ case shows that the addition of 2-EHN to a base fuel will generally result in a linear acceleration in

3 the primary heat-release stage, but without enough $\mathrm{O}_{2}$ for complete oxidation to occur a net-

4 endothermic effect will be observed. Interestingly in this case the time for transition from a net-

5 exothermic to a net-endothermic set of reaction products is delayed with increasing 2-EHN content.

6 The $\chi_{F}=0.8$ case shows that 2-EHN will accelerate the onset of endothermic pyrolysis reactions for

7 systems which may initially be exothermic, and this acceleration in endothermic pyrolysis reaction is

8 magnified by increasing 2-EHN content.

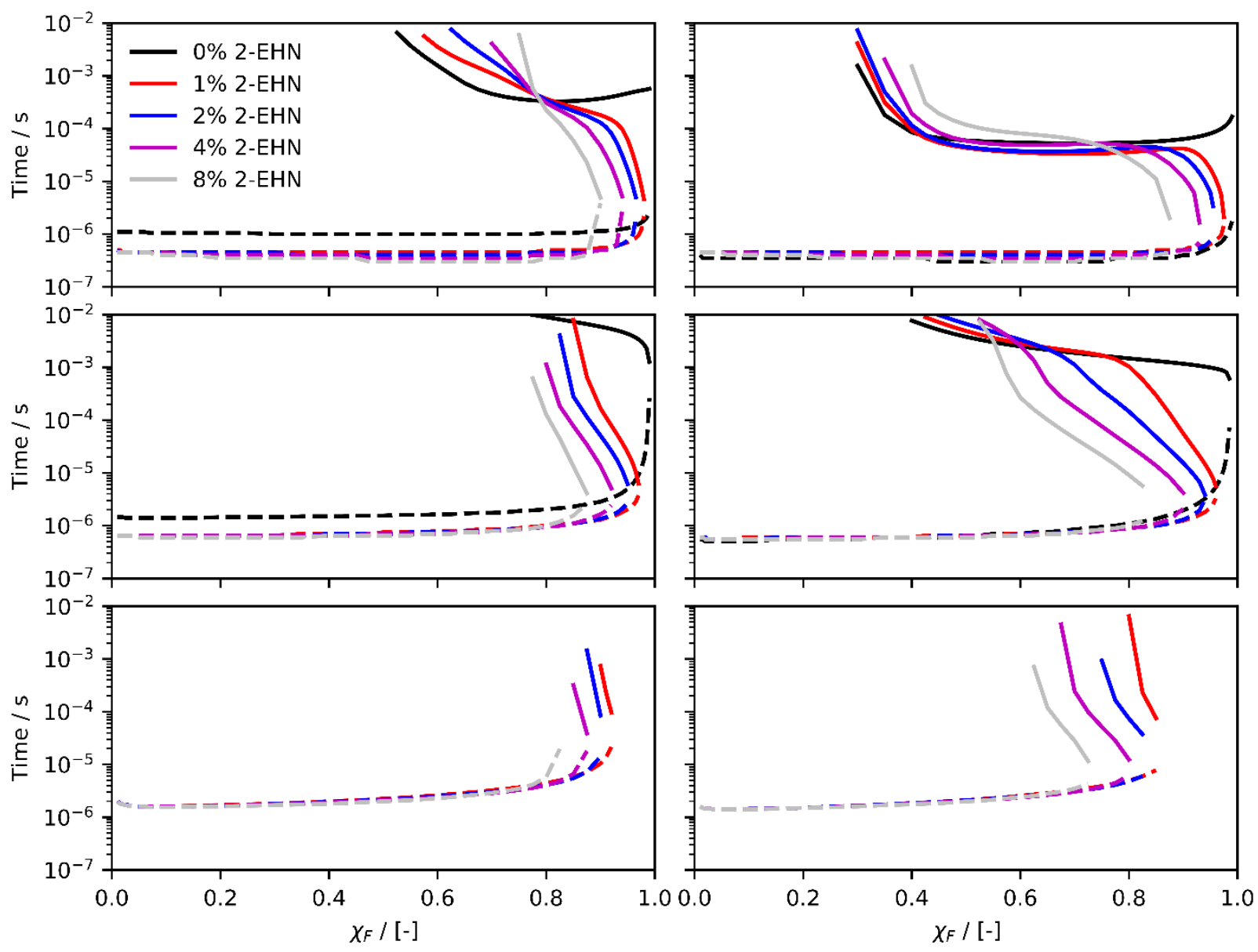

Figure 9: Contours showing characteristic timescales for the transition from exothermic to endothermic reaction, and vice-versa, for $n-\mathrm{C}_{7} \mathrm{H}_{16} / 2-\mathrm{EHN} / \mathrm{O}_{2} / \mathrm{N}_{2}$ (left) and $n-\mathrm{C}_{16} \mathrm{H}_{34} / 2-\mathrm{EHN} / \mathrm{O}_{2} / \mathrm{N}_{2}$ (right) mixtures, at total pressures of 75 bar (top), 10 bar (middle) and 1 bar (bottom), and $T / K=863$. Dashed lines correspond to the time at which the system transitions from being endothermic to exothermic (the onset of oxidation), solid lines correspond to time at which the system transitions from being exothermic to 
endothermic (the onset of endothermic pyrolysis). The colour scheme for various fuel mixtures is the same as in Figure 7 and Figure 8.

Figure 9 illustrates multiple dependencies which are likely to influence the experimental results, including variations expected to arise from (a) the chemical structure of any evaporated fuel components $\left(n-\mathrm{C}_{7} \mathrm{H}_{16} / n-\mathrm{C}_{16} \mathrm{H}_{34} / 2-\mathrm{EHN}\right)$, (b) the ratio of said fuel components to $\mathrm{O}_{2}: \mathrm{N}_{2}$ at a given total pressure, and (c), total vapour-phase gas pressure (1, 10 and 75 bar). For each fuel and pressure condition studied, we show that there are regimes where the system is initially endothermic, where it transitions from endothermic to exothermic, and where it transitions from exothermic back to endothermic once any $\mathrm{O}_{2}$ has been consumed. 2-EHN is shown to greatly accelerate both the initial and secondary endothermic pyrolysis stage, and under highly-rich conditions, it is clear that 2-EHN will induce and accelerate endothermic pyrolysis reaction relative to an alkane base-fuel which is typical of those found in diesel.

In order to understand the specific chemical species and reactions that lead to the observed endothermic effect, species mole fraction profiles and reaction path analyses have been analysed and are shown in detail in Figures S4-S11 of ESI. The results are summarised in Figure 10, where the intermediates which make major contributions to endothermicity are shown for the $\chi_{F}=0.99$ case from Figure 8, with and without 1\% 2-EHN in the mixture.

The results show that endothermic reactions occur for $n-\mathrm{C}_{16} \mathrm{H}_{34}$ in the absence of 2-EHN, largely due to the formation of stable unsaturated long-chain alkene species such as $1-\mathrm{C}_{10} \mathrm{H}_{20}(1-$ decene), and short-chain unsaturated species such as $\mathrm{C}_{2} \mathrm{H}_{4}$ and $\mathrm{C}_{3} \mathrm{H}_{6}$. The latter species are formed from multiple chemical pathways and are typical indicators of pyrolysis reactions for hydrocarbon fuels [5]. When 2-EHN is added to the fuel the initial period of endothermicity that is observed for $n$ $\mathrm{C}_{16} \mathrm{H}_{34}$ is increased by orders of magnitude of as a result of a series of chemical reaction.

The chain reaction is initiated by prompt unimolecular decomposition of 2-EHN forming heptyl radicals, $\mathrm{CH}_{2} \mathrm{O}$ and $\mathrm{NO}_{2}$. The subsequent endothermic $\beta$-scission of the alkyl radical leads to 
1 further endothermicity via the formation of $\mathrm{C}_{2} \mathrm{H}_{4}$ and $\mathrm{C}_{3} \mathrm{H}_{6}$, whose contributions to endothermicity

2 are found to be as significant as, and concomitant with, the contribution from heptyl radicals and

$3 \mathrm{NO}_{2}$. The $\beta$-scission of the heptyl radicals formed from 2-EHN leads to the formation of unstable

4 radical species (H-atom, $\left.\mathrm{CH}_{3}, \mathrm{C}_{2} \mathrm{H}_{5}\right)$ which react with the fuel forming $1-\mathrm{C}_{10} \mathrm{H}_{20}$ as the primary stable

5 intermediate. The endothermic formation of $1-\mathrm{C}_{10} \mathrm{H}_{20}$ is again observed in parallel with heptyl

6 radicals, $\mathrm{NO}_{2}, \mathrm{C}_{2} \mathrm{H}_{4}$ and $\mathrm{C}_{3} \mathrm{H}_{6}$ in Figure 10, and in Figures $\mathrm{S} 4-\mathrm{S} 11$ of ESI. The addition of 2-EHN to

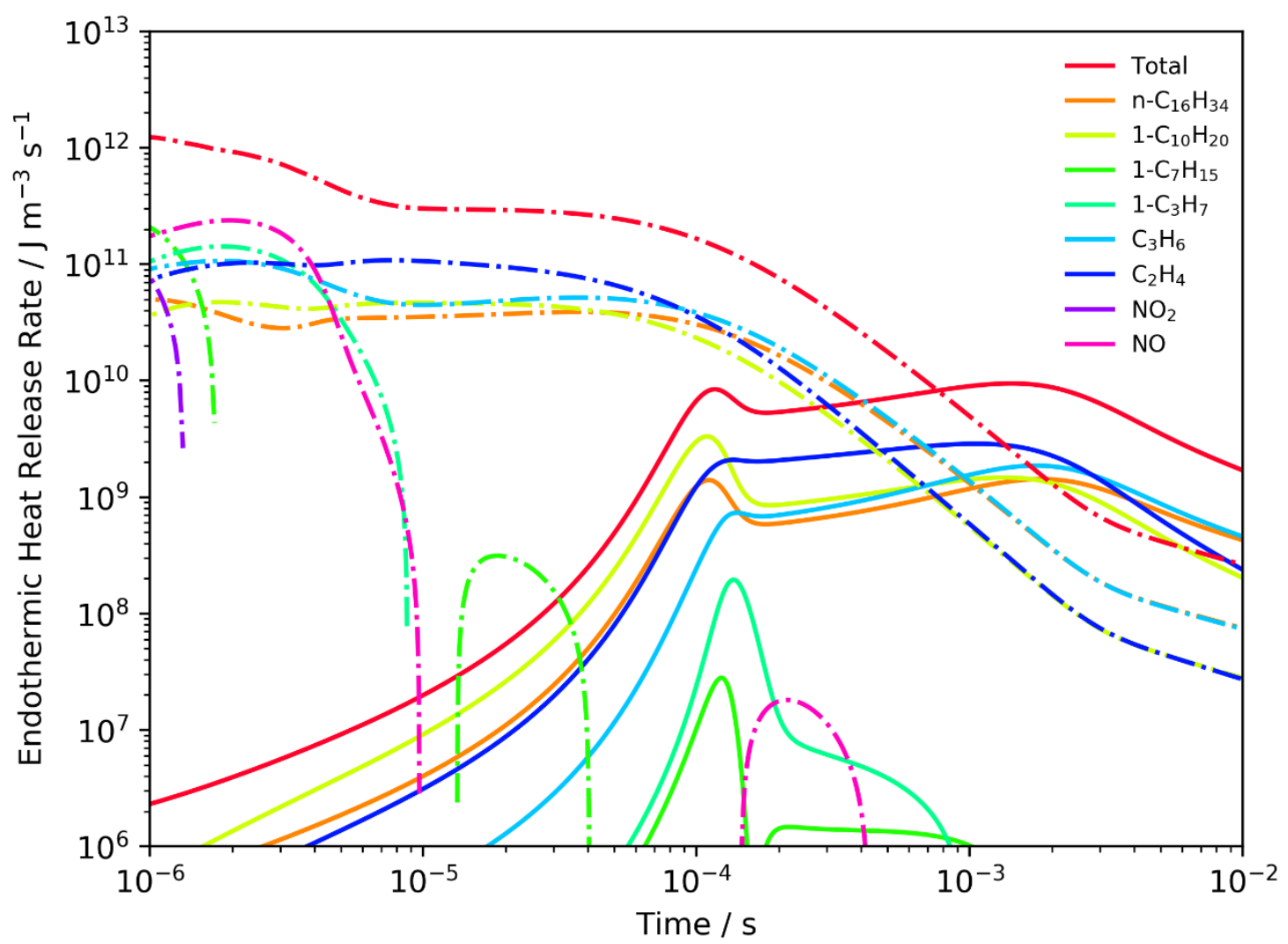

7

Figure 10: Major species contributions to the computed endothermic heat release rate for a $\chi_{F}=0.99$ mixture at $T / \mathrm{K}=863$ and $p / \mathrm{bar}=75$ with $100 \% n-\mathrm{C}_{16} \mathrm{H}_{34}$ (solid) and $99 \% n-\mathrm{C}_{16} \mathrm{H}_{34}$ with $1 \%$ 2-EHN (dashed) as the fuels.

the fuel therefore enhances endothermicity not solely as a result of its prompt dissociation and the subsequent decomposition of the heptyl radicals to small unsaturated species, but it also initiates and propagates an endothermic chain reactions that is inherent to the base fuel. Simulations have therefore been carried out to analyse the influence of fuel structure on endothermicity. 
The analysis presented in Figure 8 was repeated for cases where the alkane component of the

2 fuel was separately replaced with toluene, trimethylbenzene and $n$-propylbenzene. These fuels have high octane numbers and low cetane numbers relative to $n-\mathrm{C}_{7} \mathrm{H}_{16}$ and $n-\mathrm{C}_{16} \mathrm{H}_{34}$, and are therefore more typical of gasoline fuel components. However, their chemical structure differs substantially

5 from the diesel surrogates we use in that their aromatic moiety leads to weaker $\mathrm{C}-\mathrm{H}$ bonds which may lead to a faster chain initiation step, but the lack of a substantial alkyl side chain is likely to lead to an overall reduced oxidation and pyrolysis rate. The results are presented in S12-S15 of ESI and they illustrate that no significant endothermicity is observed for these components with or without 2EHN added to the fuel. The extent of endothermicity appears to be proportional to the length of the alkyl chain with the time of onset and the magnitude of endothermicity following the trend:

$$
n-\mathrm{C}_{16} \mathrm{H}_{34}>n-\mathrm{C}_{7} \mathrm{H}_{16}>>\text {-propylbenzene }>\text { trimethylbenzene } \approx \text { toluene }
$$

This supports a mechanism whereby 2-EHN is not solely responsible for endothermicity, rather, it is initiating an endothermic chain reaction which is intrinsic to fuel components with a sufficiently long alkyl chain. Whilst the modelling results presented herein are idealised, they are among the first to examine these chemical kinetic effects in detail, and further studies on the extent and mechanism of endothermic reaction for different fuel components and fuel additives are warranted based on our findings. In particular experimental studies of diesel surrogate mixtures with and without radical initiators, combined with detailed chemical kinetic modelling analyses, would provide further insight into this phenomenon.

\section{Conclusions}

The implications of the endothermicity of pyrolytic reaction for practical combustion systems have been largely confined to the study of aviation fuels; however this work has provided evidence that such reactions can influence the measured pressure in a Combustion Research Unit designed to emulate diesel combustion. When diesel fuel is injected into a constant volume vessel, the pressure 
1 initially decreases before the exothermic heat release causes the pressure to increase. The initial

2 pressure decrease is conventionally attributed to evaporation but endothermicity is shown to be

3 enhanced upon addition of 2-EHN to the mixture.

Kinetic modeling results highlight that there are critical regions of mole-fraction space where

5 the partial-oxidation of hydrocarbon mixtures leads to an endothermic set of reaction products. In the

$6 \mathrm{CRU}$, where initial chemical reaction is likely to happen at the rich interface between liquid fuel and oxidiser, one should consider that endothermic pyrolysis can contribute to the pressure-drop observed in apparatus such as the CRU. The subsequent addition of 2-EHN to the chemical surrogates considered herein shows some interesting and complex behaviours as one varies the chemical structure of a base fuel, and the ratios of base fuel:2-EHN:air within a gas-phase mixture.

11 In line with our experiment, modeling results highlight conditions where 2-EHN clearly accelerates the onset of ignition, but despite this there are conditions where its addition leads to significantly enhanced and accelerated endothermicity in comparison to pure hydrocarbon components. Modeling analysis shows that this effect is the result of a radical chain reaction that is initiated by 2-EHN, and the endothermic effect is also dependent on the structure of the base fuel, and aromatic components with short alkyl side chains show less propensity to contribute to endothermicity than the long-chain alkyl components we have studied.

With respect to the demarcation of the end of a physical delay period and the start of the chemical delay period for liquid fuel sprays, it appears that one should consider not just the influence of liquid fuel evaporation, but also the influence of endothermic reactions, particularly in instances where the fuel structure is varied and radical initiators are present.

\section{Acknowledgements}

The authors would like to thank Fueltech for permission to publish the schematic diagram of the Combustion Research Unit and Jens Schreckenberg for his assistance with the project. The involvement of Dr Hichem Hakka in the work was financed under the European Commission Marie 
1 Curie Transfer of Knowledge Scheme (FP7) pursuant to Contract LOWCAFF-251492. The

2 involvement of Dr Kieran Somers in the work was financed by the European Commission pursuant 3 to Contract PIAP-GA-2013-610897 GENFUEL. The authors declare no competing interests. 


\section{$1 \quad$ References}

2 1. MacDonald ME, Davidson DF, Hanson RK, Pitz WJ, Mehl M, Westbrook CK. Formulation of an RP-1 pyrolysis surrogate from shock tube measurements of fuel and ethylene time histories. Fuel 2013;103:1051-59.

2. MacDonald ME, Davidson DF, Hanson RK. Decomposition measurements of RP-1, RP-2, JP-7, n-dodecane, and tetrahydroquinoline in shock tubes. J. Prop. Power 2011;27:981-9.

3. Dahm KD, Virk PS, Bounaceur R, Battin-Leclerc F, Marquaire PM, Fournet R, Daniau E, et al. Experimental and modeling investigation of the thermal decomposition of $\mathrm{n}$-dodecane. $\mathbf{J}$ Anal. App. Pyrol. 2004;71:865-81.

4. Herbinet O, Marquaire PM, Battin-Leclerc F, Fournet R. Thermal decomposition of n-dodecane: Experiments and kinetic modeling. J Anal. App. Pyrol. 78;2007:419-29.

5. Hakka HM, Cracknell RF, Pekalski A, Glaude PA, Battin-Leclerc F. Experimental and modeling

10. American Society for Testing and Materials. "Standard Test Method for Cetane Number of Diesel Fuel Oil”. 2010. ASTM D613-10a. 
1 11. Yu TC, Uyehara OA, Myers PS, Collins RN, Mahadevan K. Physical and chemical ignition delay in an operating diesel engine using the hot-motored technique. SAE Technical Paper 560061 1956: doi:10.4271/560061.

12. Chiang CW, Myers PS, Uyehara OE. Physical and chemical ignition delay in an operating diesel engine using the hot-motored technique-part II. SAE Technical Paper 600057 1960: doi:10.4271/600057.

13. Ryan TW. Correlation of physical and chemical ignition delay to cetane number. SAE Technical Paper 852103 1985: doi:10.4271/852103.

14. Ryan TW, Stapper B. Diesel Fuel Ignition Quality as Determined in a Constant Volume Combustion Bomb, SAE Technical Paper. 870586 1987: doi: 10.4271/870586.

15. Ryan TW, Callahan TJ. Engine and constant volume bomb studies of diesel ignition and combustion, SAE Technical Paper 881626 1988): doi:10.4271/881626.

16. Aradi AA, Ryan TW. Cetane Effect on Diesel Ignition Delay Times Measured in a Constant Volume Combustion Apparatus, SAE Technical Paper. 952352. (1995) doi: 10.4271/952352.

17. Zheng Z, Badawy T, Henein N, Sattler E. Investigation of physical and chemical delay periods of different fuels in the ignition quality tester. J. Eng. Gas Turbines Power 2013; 135: 061501061501-11. GTP-12-1335. doi: 10.1115/1.4023607.

18. Hu Z, Somers LMT, Davies T, McDougall A, Cracknell RF. A study of liquid fuel injection and combustion in a constant volume vessel at diesel engine conditions. Fuel 2013;107: 63-73.

19. Rabl S, Davies TJ, McDougall AP, Cracknell RF. Understanding the relationship between ignition delay and burn duration in a constant volume vessel at diesel engine conditions. Proc. Comb. Inst. 2015;35: 2967-74.

20. Joshi U, Zheng Z, Henein N, Sattler E. An investigation on sensitivity of ignition delay and activation energy in diesel combustion. J. Eng. Gas Turbines Power. 2015; 137(9):091506091506-8 GTP-14-1638. doi: 10.1115/1. 
1 21. Higgins B, Siebers D, Mueller C, Aradi A. Effects of an ignition-enhancing, diesel-fuel additive on diesel-spray evaporation, mixing, ignition, and combustion. Twenty-Seventh Symposium (International) on Combustion 1998; 27:1873-80.

4

5

22. Ranzi E, Frassoldati A, Stagni A, Pelucchi M, Cuoci A, Faravelli T. Reduced kinetic schemes of complex reaction systems: fossil and biomass-derived transportation fuels. International Journal of Chemical Kinetics 2014; 46:512-42.

23. Mechanisms downloaded from, http://creckmodeling.chem.polimi.it/. 2017 [accessed 03/05/2017].

24. Andrae JA, Semi-detailed kinetic model for gasoline surrogate fuel interactions with the ignition enhancer 2-ethylhexyl nitrate. Energy\&Fuels 2015; 29:3944-52.

25. Zhang K, Banyon C, Bugler J, Curran HJ, Rodriguez A, Herbinet O, et al. An updated experimental and kinetic modeling study of n-heptane oxidation. Combust. Flame 2016;172:116-35.

26. Goodwin DG, Moffat HK, Speth RL. Cantera: An object- oriented software toolkit for chemical kinetics, thermodynamics, and transport processes. http://www.cantera.org, 2017. Version 2.3.0. doi:10.5281/zenodo.170284\#

17

8

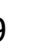

(1)

1

2

3

.

5

6




\section{Figure Captions:}

2 Figure 1: Pressure-Time records and injection-nozzle needle-lift trace with identification of the

3 various points of interest. Adapted with permission from [14].

4 Figure 2: Schematic diagram of the Combustion Research Unit. (Reproduced with permission from $5 \quad$ Fueltech)

6 Figure 3: Pressure traces for the nine injection conditions in. The solid line is for EN590 diesel and 7 the dashed line is for EN590 diesel with 1\% mass 2-EHN.

8 Figure 4: Comparison of the predictions of the reduced $n-\mathrm{C}_{7} \mathrm{H}_{16}$ kinetic model of Ranzi et al. [22] 9 with jet-stirred reactor measurements of ultra-rich $n-\mathrm{C}_{7} \mathrm{H}_{16} / \mathrm{O}_{2} / \mathrm{He}$ oxidation of Hakka et al. [5] at 101.06 bar, $\varphi=3$ in helium bath gas. Top: Residence time $=1 \mathrm{~s}$, mole fraction of fuel $1 \times 10^{-3}$. Bottom: 11 Residence time $=2 \mathrm{~s}$, mole fraction of fuel $5 \times 10^{-3}$.

12 Figure 5: Gas-chemistry heat release rates $\left(\mathrm{J} \mathrm{m}^{-3} \mathrm{~s}^{-1}\right)$ for stoichiometric fuel-air mixtures of $n$ 13 heptane and $n$-hexadecane, with and without $1 \%$ 2-ethylhexylnitrate additive, at $T / \mathrm{K}=863$ and $p /$ bar $14=75$. Inset: heat release rates vs. time for the first $10 \mu$ s of chemical reaction, units for $x$ and $y$ axes 15 are the same as main figure.

Figure 6: Reaction enthalpies as a function of fuel mole fraction at the lowest (left) and highest

17 (right) experimental conditions of temperature and pressure. A positive reaction enthalpy indicates net-endothermic reaction, and vice-versa for a negative reaction enthalpy.

Figure 7: Influence of increasing gas-phase 2-EHN mole fraction on the reaction enthalpy for a 10 ms simulation of $n-\mathrm{C}_{7} \mathrm{H}_{16}$ and $n-\mathrm{C}_{16} \mathrm{H}_{34}$ fuel-oxidiser mixtures at $863 \mathrm{~K}$ and 75 bar.

21 Figure 8: Time-dependent reaction enthalpy for mixtures with varying $n-\mathrm{C}_{16} \mathrm{H}_{34}$ :2-EHN ratios and 22 fuel:oxidiser ratios at $T / \mathrm{K}=863$ and $p /$ bar 75 bar. 
1 Figure 9: Contours showing characteristic timescales for the transition from exothermic to 2 endothermic reaction, and vice-versa, for $n-\mathrm{C}_{7} \mathrm{H}_{16} / 2-\mathrm{EHN} / \mathrm{O}_{2} / \mathrm{N}_{2}$ (left) and $n$ - $\mathrm{C}_{16} \mathrm{H}_{34} / 2-\mathrm{EHN} / \mathrm{O}_{2} / \mathrm{N}_{2}$ 3 (right) mixtures, at total pressures of 75 bar (top), 10 bar (middle) and 1 bar (bottom), and at a 4 temperature of $T / \mathrm{K}=863$. Dashed lines correspond to the time at which the system transitions from 5 being endothermic to exothermic (the onset of oxidation), solid lines correspond to time at which the 6 system transitions from being exothermic to endothermic (the onset of endothermic pyrolysis). The 7 colour scheme for various fuel mixtures is the same as in Figure 7 and Figure 8.

8 Figure 10: Major species contributions to the computed endothermic heat release rate for a $\chi_{F}=0.99$ 9 mixture at $T / \mathrm{K}=863$ and $p /$ bar $=75$ with $100 \% n-\mathrm{C}_{16} \mathrm{H}_{34}$ (solid) and $99 \% n-\mathrm{C}_{16} \mathrm{H}_{34}$ with $1 \%$ 2-EHN 10 (dashed) as the fuels. 